Indian J Anim Health (2022), 61(1): 178- 179

DOI: https://doi.org/10.36062/ijah.2022.06621

\title{
Prevalence of gastrointestinal parasites in game birds of Puducherry region
}

\author{
S. Sivaprakash ${ }^{1 *}$, D. Selvi ${ }^{1}$, P. Vijayalakshmi ${ }^{1}$, K. Rajkumar ${ }^{1}$, A. Abiramy @ Prabhavathy ${ }^{1}$ and \\ N. Devadevi ${ }^{1}$
}

${ }^{1}$ Department of Veterinary Medicine, Rajiv Gandhi Institute of Veterinary Education and Research, Puducherry - 605 009, India

\begin{abstract}
Cock fight, an important traditional game show, has been more popular in many parts of India since ancient times. The birds are commonly reared by a certain group of people in their households for their livelihood and as a pride. The study was conducted to investigate the prevalence of gastrointestinal parasites in game birds in and around Puducherry region. Forty-eight cloacal swabs from game birds were collected from eight different regions of Puducherry. The droppings were examined for the presence of ova and oocysts of the endoparasites by direct microscopic examination. Nematodes $\mathbf{5 4 . 1 6 \% )}$ were the only parasites recorded, of which Capillaria sp. $(33.33 \%)$ was most prevalent, followed by Ascaridia galli $\mathbf{2 9 . 1 6 \% )}$ ) and Heterakis gallinarum (20.83\%). Coccidia oocysts were also recorded in $35.41 \%$ of birds. Concurrent nematode and coccidia were recorded in $\mathbf{1 8 . 7 5 \%}$ of birds. The infected birds were further treated with anthelmintics.
\end{abstract}

Key words: Anthelminthics, Capillaria, Coccidia, Nematodes

\section{Highlights}

- Intensity of gastrointestinal parasites in game birds were recorded.

- Internal parasites - an important cause of loss in game birds.

- Deworming and hygienic rearing of game birds helps in prolonging the longevity of game birds.

Game bird rearing is quite popular in many parts of India. Game birds are an integral part of our tradition, and they are most commonly reared in households in local villages of India (Hasan et al., 2018). Cock fight is a blood sport between two cocks (roosters) held in a ring called a cockpit, and it has been more popular in southern states of India including Tamilnadu and Puducherry since ancient times. It is acknowledged as one of the "64 arts" to be mastered by scholars in old Tamil literatures. The wide variety of breeds includes Black Aseel, Peela Aseel, Java, Galva, Yakuth, Reja and Dummer.

The birds kept in the households are under constant stress due to captivity and are prone to several parasitic diseases. Caged birds are infected by a wide variety of intestinal parasites in which nematodes and protozoa are common. Parasitic infections are the major cause of financial loss in poultry industries. The parasites in the gastrointestinal tract cause loss of appetite, emaciation, diarrhoea, reduced egg production, retarded growth and reduce the economic value of the birds (Parsani et al., 2001). Kulkarni et al. (2001) opined that the most significant constraint on poultry production is helminthiosis in humid tropical climatic conditions of India. Later, Hasan et al. (2018) reported that parasitism is one of the main problem in game birds which affects the health and immune status. Hence, the present study was planned to determine the prevalence of gastrointestinal (GI) parasites and their impact on the growth of the game birds in Puducherry region.

To study the prevalence of gastrointestinal parasites of the game birds, 48 samples from the eight different villages of Puducherry such as Periyakalpet, Thavalakuppam, Bahour, Villianur, Pillaiyarkuppam, Madagadipet, Mannadipet and Kariyamanicam were collected. The droppings were collected aseptically from the cloacae of the birds by using cotton swabs. The swabs were examined for the presence of ova and oocysts of the parasites by direct

*Corresponding Author, E Mail: drsivaprakash82@gmail.com 
microscopic examination. During sample collection, relevant epidemiological details regarding host and environment such as age, sex, rearing system and feeding habit of birds were recorded. The cloacal swabs were examined on the same day by direct microscopic examination as per the standard procedure. The eggs of the helminth parasites and oocysts of the protozoa were identified by their characteristic features (Soulsby, 1982).

During this study, a total of 48 game birds were examined, of which $26(54.16 \%)$ were found infected with gastrointestinal parasites. Nematodes were the only parasites recorded in the samples on the basis of characteristic morphological features. The overall prevalence of Capillaria sp., Ascaridia galli and Heterakis gallinarum in game birds were $33.33 \%, 29.16 \%$ and $20.83 \%$, respectively. Capillaria sp. was found to be the most prevalent, followed by Ascaridia galli and Heterakis gallinarum in the game birds of Puducherry.

Alongside, the prevalence of Eimeria spp. was $35.41 \%$. Concurrent nematode and coccidia were recorded in $18.75 \%$ of birds. This study is similar to the findings of Akinboye et al. (2017) from North America, where game birds were infected with $38.0 \%$ of intestinal parasites. Also, Borecka et al. (2013) recorded

\section{REFERENCE}

Akinboye DO, Ogunfeitimi AA, Fawole O, Agbolade O, Ayind O et al., 2017. A comparison of prevalence and burdens of parasitic infections in young and adult exotic birds. Nigerian J Parasitol, 1: 35-38

Borecka A, Gawor J and Zieba F, 2013. A Survey of intestinal helminths in wild carnivores from the Tatra National Park, southern Poland. Ann Parasitol, 59(4): 169-172

Hasan T, Mazumder S, Hossan MM, Hossain SM, Begum N et al., 2018. Prevalence of parasitic infections of game birds in Dhaka city corporation, Bangladesh. Bangladesh J Vet Med, 16(1): 1-6, doi: 10.3329/bjvm.v16i1.37366

Heyradin H, Hassen C, Yosef D and Molalegne B, 2012. Gastrointestinal helminthes are highly prevalent in love birds of selected districts of Eastern Shewa zone, Ethiopia. Pakistan J Biol Sci, 15(6): 284-289
Ascaridia galli (34\%) and Eimeria spp. (23\%) in Poland from game birds.

The prevalence of gastrointestinal parasites was relatively higher in females $(45.83 \%)$ than in males $(8.33 \%)$. The result of the present study was similar to the observations of Heyradin et al. (2012), who reported male birds generally exhibited resistance against parasites than female birds. Also, the proportions of male birds are less compared to the female birds in the present study. The affected birds were further treated with broad spectrum anthelmintics. Phiri et al. (2007) reported that regular deworming improves the growth and subsequent body weight gain in birds. Since there is no report about the prevalence of gastrointestinal parasites of game birds in India, the result obtained in the present study highlights the awareness on the seriousness of internal parasitism in game birds. Hence the prophylactic deworming regimen with antinematodal drugs has to be followed in game birds.

Conflict of interest: Authors have no conflict of interest in this study.

Author's contribution: SS: Conducted the experiment; DS \& PV: Designing and visualization of the study; all the authors involved in data analysis, manuscript draft preparation and editing.

Kulkarni GM, Narladkar BW and Deshpande PD, 2001. Helminthicinfections in desi fowl(Gallus gallusdomesticus) in Marathwada region. J Vet Parasitol, 15: 137-139

Parsani HR, Momin RR and Bhuva CN, 2001. Parasitic infections among captive birds at Sakkarbagh Zoo, Junagadh, Gujarat. Zoos Print J, 16(4): 462-464, doi: 10.11609/JOTT.ZPJ.16.4.462-4

Phiri IK, Phiri AM, Ziela M, Chota A, Masuku M et al., 2007. Prevalence and distribution of gastrointestinal helminths and their effects on weight gain in free-range chickens in Central Zambia. Trop Anim Health Prod, 39(4): 309-315, doi: 10.1007/s11250-007-9021-5

Soulsby EJL, 1982. Helminths, Arthropods and Protozoa of Domesticated Animals, 7th edn., Bailliere Tindall, London

Received - 14.08.2021, Accepted - 15.12.2021, Published - 17.02.2022 (Online), 01.06.2022 (Print)

Section Editor: Prof. S. N. Joardar, Associate Editor 